\title{
Depicting cross-cultural interaction: figurative designs in wood, earth and stone from south-east Australia
}

\author{
PAUL S.C. TAÇON, BARRINA SOUTH AND SHAUN BOREE HOOPER
}

\begin{abstract}
We examine Aboriginal wooden artefacts traded between European and Aboriginal Australians in south-east Australia in order to gain insight into the impact of cross-cultural interaction on Aboriginal art traditions. Although we focus on wooden objects with figurative designs made and exchanged over the past 150 or more years, as well as their links to earlier ground, tree and rockart traditions, the study contributes to a larger understanding of cultural change not well documented with ethnography. Information from 469 individual pieces in 90 private and public collections, is summarised, along with the development of individual, community and regional styles. A theory about the role of such material culture during changing times in south-east Australia is outlined. More generally, it is argued that material culture both mediates and expresses change, with figurative motifs and storytelling through pictures particularly effective when communicating to diverse groups of people of varying cultural and linguistic backgrounds.
\end{abstract}

\section{Objects and images, identity and land}

One of the more significant forms of interaction between Aboriginal and non-Aboriginal people that has impacted on traditional indigenous material culture since contact is that which revolved around trade in artefacts. Such trade always had important political, economic and identity ramifications but these have only recently been articulated (e.g. Kleinert 1994; Wells 1993 for south-east Australia). In this study, the focus is not so much on the political or economic but rather on the ways in which certain objects made for trade functioned to communicate aspects of indigenous identity and experience considered important by both Aboriginal makers and non-Indigenous consumers. There also is a special focus on concerns for and connections to land as reflected in various forms of artefact trade or manufacture as well as the imagery engraved, painted or burnt into trade objects from south-east Australia. For instance, the production of artefacts for sale allowed people to maintain a connection to country and continue the connection to knowledge of resources, manufacturing methods and templates of artefacts. Some of the more important study aims are:

People and Place Research Centre, Australian Museum, 6 College St., Sydney 2010. Email: pault@austmus.gov.au
1. To chart the nature of imagery on wooden objects made for exchange during 1850-1970 in south-east Australia.

2. To examine the role of material culture in asserting and shaping Aboriginal identity in the changing southeast Australian social environment.

3. To discern possible relationships between artefacts, images and connections to traditional lands.

4. To determine some sources of imagery and inspiration, including traditional sources, such as earlier artefact adornment traditions, rock-art sites and ethnographically reported ceremonial grounds, and transcultural or recent historical influences that commemorate anniversaries, special events like the opening of the Sydney Harbour Bridge, and experience in larger society.

5. To map distributions of resources, manufacturing methods and templates and investigate the relationship between mission/reserve based work and traditional work.

Howard Morphy (1998) has commented on the perceived loss of information and lack of understanding of the early figurative art of south-east Australia. This is similar to the situation with art found in most Australian archaeological contexts, especially rock-art, although there is a range of methods available for its scientific study (e.g. see Chippindale and Taçon 1998; Morphy 1989; Ross 2001). For the Australian south-east, Morphy proposed that multi-faceted research projects which combine object analysis with information from archival sources and, when possible, oral history or analogy from other Aboriginal societies, would be most fruitful:

\footnotetext{
Although so little information survives, the possibility of recovering more through analysis of the objects is considerable. This research is in its infancy. The first task is to collect together all the fragments of information about context and meaning, relate them together and reconnect them to the objects themselves. This attempt at reconnection is made easier by the knowledge that now exists about the art and artefacts of neighbouring societies to the north whose histories are better known. But it is most important to connect artefacts to the historical processes of which they are a part, to the Aboriginal people who are the descendants of their makers and who provide avenues to understanding. The information they hold helps in the reconstruction of past patterns and also serves to incorporate the objects into the present.

Eventually much will be learnt by carrying out such research and from the form of the objects; at present it is
} 
possible only to glimpse their significance, to grasp intuitively the ordered worlds they were once part of and to reflect on the aesthetic effect they may have had (Morphy 1998: 336)

Besides having aesthetic effects, Indigenous artefacts, as a medium of exchange, also inform about interactions, relationships, symbolic communication between different groups of people, trade and economy at many levels. However, their participation in daily life, exchange on special occasions and the semiotics of the designs themselves can yield insight into many aspects of Indigenous 'lifeways', as has been shown in many parts of the world (e. g. Jules-Rosette 1984; Kleinert 1994; Phillips and Steiner 1999; Sculthorpe 1996; Vastokas 1994; Wells 1993). Vastokas (1994:337) highlights five essentials of theory in this regard:

(1) the meaning of artifacts, including works of visual "art", is constituted in the life of the objects themselves, not in words or texts about them; (2) the artifact is not an inert, passive object but an interactive agent in sociocultural life and cognition; (3) the signification of the artifact resides in both the object as a self-enclosed material fact and in its performative, "gestural" patterns of behaviour in relation to space, time, and society; (4) the processes, materials, and products of technology, especially those of a society's dominant technology, function as cultural metaphors at many levels and in many socio-cultural domains; and (5) theoretical insights derive, not from theorizing in the abstract, but from direct observation and experience of the phenomenal world of nature and culture.

In this context it also is important to emphasise that artefacts are objects rather than subjects and do not produce or express cultural change while standing as fixed and stable entities themselves (Thomas 1991:208). But the ways in which artefacts participate in much wider systems of change has only very recently been explored on a global basis (e.g. Appadurai 1986; Phillips and Steiner 1999; Torrence and Clarke 2000). The interplay between social change, material culture production, imagery, meaning and further change is often complex but necessarily important to define in any study that seeks to understand the full role that objects play during turbulent times. As Thomas (1991:206) emphasises:

Objects have been central in these transcultural histories; they have often marked alterity and particular strategies for dealing with it - - through appropriation and incorporation or distancing and recontextualizing. Some things mark the (partial) acquisition of the capacities or attributes of the other; others express indeterminacy and a bridge between apparently incompatible systems; others now stand for totalities formerly unrepresented, which are discovered, as explicit forms, through the process of contact.

Finally, it is important to note that artefacts intended primarily for internal consumption, indigenous mediation and/or exchange often differ in subtle or significant ways from those made and designed explicitly for transcultural mediation and sale (Amos (1978) for a specific example and Graburn (1976) more generally). This is important for wooden objects from south-east Australia as initially those more often used internally were adorned with geometric motifs (Cooper 1994) while those made for external consumption are dominated by figurative motifs. However, wooden objects with geometric motifs were also traded, primarily in the nineteenth and early twentieth centuries. Market demand may have influenced the inclusion of some geometric designs but such marks may also be related to painted body art that certainly communicated aspects of identity to other Aboriginal people. For instance, Cooper (1994) emphasises there is "no doubt that different tribal areas were characterised by different two- and three-dimensional designs on their wooden objects' (1994:108). Furthermore, Kleinert (2000:241) argues 'The evident parallels between the rock art, carved wooden weapons, possum-skin cloaks, carved trees (dendroglyphs), cicatrices, and body designs of the region, make it likely that these graphic elements encoded restricted knowledge as they do elsewhere in Aboriginal communities today'. But Cooper (1994:108-09) also notes that 'the possibility of sale to Europeans stimulated a greater and in many instances very creative use of figurative and naturalistic design on artefacts'. When geometric motifs do appear on twentieth century objects made for external markets they are usually at the borders and margins. Since the 1920 s, the geometric appears marginalised by the figurative similarly to the way Aboriginal people themselves were marginalised by Europeans. However, the geometric designs are repeatedly and purposely placed to reflect identity; they continue to be used by members of the south-east Australian Aboriginal community to identify the makers of objects.

\section{The sample: wooden objects from south-east Australia}

South-east Australia has been variously described in both physical and cultural terms. For the purposes of this project it includes southern Queensland, New South Wales, Victoria and southern South Australia, south of Lake Eyre and Coober Pedy. The westernmost community is Yalata, on the Nullarbor Plain. The northernmost is Taroom, Queensland. Tasmania was not included because of a lack of material. North Queensland, Western Australia and the Northern Territory have not been included because transformations in art and material culture have been well studied for significant parts of these regions (especially Hermannsburg, other parts of central Australia and Arnhem Land) and because the people of these regions interacted in different circles. However, some comparable objects from these regions were noted and, where appropriate, analogies have been made to aid interpretation. For instance, the work of one Charlotte Waters artist, Jim Kite (Erlikiliaka), was examined because it underwent similar changes from geometric to figurative and because he travelled to Sydney in his youth. 
Wooden objects were chosen for study because they were the most abundant in both private and public collections, had more elaborate stories or documentation, had a greater range of adornment and had the most potential for conveying information about design change in relation to context of production. Consequently, the study focuses on objects made by men but this is not to deny that women played significant roles in artefact trade nor that women's objects were immune to change brought about by transcultural situations (e.g. Kleinert 1994; Wells 1994).

The Australian Museum's Indigenous Australian collections from the south-east are a primary source of material but a number of regional and national museum collections were also studied. Importantly, private collections retained by the Indigenous and non-Indigenous public were also researched for additional information and comparative data that enhances the museum material, which is not always well documented. Material culture items include boomerangs, shields, clubs, walking sticks and other wooden objects adorned with imagery. Associated archives, photographs and oral histories were used to better interpret the objects. Carved emu eggs and other objects, such as baskets and those associated with body adornment, were not included, being the subject of a related study.

In 1998-99, a pilot study was undertaken on a segment of traded material. This included the documentation, description and interpretation of wooden Aboriginal objects, with painted, carved or pokerwork depictions of people, animals, plants and landscapes, made in southeastern Australia between 1850 and 1970 . Eight primary types of object were studied but boomerangs made up the vast majority. In order of frequency the types were: boomerangs, shields, spear throwers, clubs, containers (coolamons, plates, boxes), walking sticks, stockwhip handles, bullroarers and other miscellaneous objects (including table tops). These and other objects were found to contain imagery that expresses relationships to landscapes, illustrates traditional cultural practices, shows contact situations and charts changing circumstances brought about by European settlement. The objects thus became a medium of exchange for and between Indigenous and non-Indigenous, eventually developing into a kind of tourist industry.

In the pilot study we began to define individual, community and regional styles of depiction, along with the types of messages these objects convey, to learn who made them and why. Museums across Australia, Indigenous elders and communities as well as over 120 members of the public participated in the project by donating objects and giving access to both public and private collections or information. A total of 469 objects were studied, 256 of which are in private hands and in many cases have associated oral histories.

Objects were comprehensively described with particular attention paid to the form, style, subject matter, technique, colour and naturalism of the design. Place of origin, details about the maker and/or community and the history of the object were recorded. All objects were photographed. Written notes and a standard recording form specifically designed for the project were used. Stylistic attributes, archival material and written documentation were drawn upon to define style regions, schools and communities of artists; wherever possible objects were attributed to known individuals. Attributed objects were compared to undocumented work in terms of form and style. In this way, some objects of unknown origin were assigned to regions, communities and, in some cases, individuals.

The age of objects was established where possible. Unfortunately, only a few pieces have precise dates of manufacture associated with them but chronology can be derived from internal evidence in the works, such as formal qualities, subject matter, materials, techniques and so forth (Vastokas 1987:24). In addition, chronology and provenance of works can be enhanced through the use of historical evidence by examining any records of documentation and exchange extant in other archives.

The subject matter depicted with figurative designs was studied in terms of what it can tell us of Aboriginal society during the contact period, how it relates to the natural environment and what sorts of meanings are conveyed through the arrangement of particular design elements. Function, iconography (specific meaning) and implicit or general meaning were explored, along with the relationship of the material to other changes in society during the period in which it was made. Elsewhere, Sayers (1994:16) has demonstrated the utility of this approach to the study of nineteenth century Aboriginal drawings on paper, noting relationships between people, animals and places in the iconography.

Following the art historical approach advocated by Morphy (1989:3), artefacts, particularly those with figurative designs, were analysed to:

identify images or components, determine what the images are and locate them in time and space; determine how images represent and encode meaning; examine relationships between images and consider composition; where possible, find out what the images and components mean; interpret images/compositions as part of wider cultural systems.

Research included the purchase of outstanding objects at auction and the study of objects in various museum collections. In July 1998 an article about the project appeared in the Sydney Morning Herald, with an appeal for the public to get involved. This led to over 150 phone calls, letters and faxes, as well as an appearance on the Today Show and several radio programs. Members of the public, both Indigenous and nonIndigenous still contact the Australian Museum, although the frequency has dropped to 2-5 calls or letters a month. Most private collections consist of 1-5 artefacts of interest but there are a few large, remarkable and well-documented collections, including one in Melbourne of over 100 pieces (larger than the national and most state museum collections) 


\begin{tabular}{lllll}
\hline Subject & Coastal NSW & Inland NSW & Victoria (Lake Tyers) & Flinders Ranges \\
\hline Kookaburra & $28.5(100)$ & $3.34(4)$ & $31.0(45)$ & \\
Kangaroo & $22.2(78)$ & $9.2(11)$ & $27.6(40)$ & $22.6(76)$ \\
Emu & $18.8(66)$ & $27.7(33)$ & $20.7(30)$ & $19.6(66)$ \\
Possum & $13.1(46)$ & & & \\
Human & $10.3(36)$ & $19.3(23)$ & $2.1(3)$ & $15.43(52)$ \\
Koala & $4.6(16)$ & $5.0(6)$ & $5.52(8)$ & \\
Other bird & $1.1(4)$ & $5.9(7)$ & $7.6(11)$ & $3.3(11)$ \\
Snake & $0.6(2)$ & $7.6(9)$ & & $7.1(24)$ \\
Lizard/goanna & $0.6(2)$ & $5.9(7)$ & & $5.04(17)$ \\
Insect & $0.3(1)$ & $5.0(6)$ & & $11.6(39)$ \\
Fish & & $3.34(4)$ & $4.1(6)$ & \\
Lyrebird & & $1.7(2)$ & $1.4(2)$ & $0.6(2)^{*}$ \\
Dog & & & $5.93(20)$ \\
Swan & & & & $5.04(17)$ \\
Duck & & & & $1.5(5)$ \\
Eagle & & & & $1.19(4)$ \\
Horse & & & & $1.19(4)$ \\
Other & & & & \\
\hline
\end{tabular}

Table 1: Animal subject matter by percent and (number) on wooden objects by area. ${ }^{*}$ Does not include 6 composite scenes of dogs catching kangaroos or emus.

\begin{tabular}{lllll}
\hline Subject & Coastal NSW & Inland NSW & Victoria (Lake Tyers) & Flinders Ranges \\
\hline Spear & $29.0(31)$ & $14.3(4)$ & & $18.5(12)$ \\
Boomerang & $17.8(19)$ & $14.3(4)$ & $49.2(32)$ \\
Spear-thrower & $3.7(4)$ & $3.6(1)$ & & $1.5(1)$ \\
Shield & $1.9(2)$ & $10.7(3)$ & $12.3(8)$ \\
Club & $0.9(1)$ & $3.6(1)$ & \\
Hafted axe & & $3.6(1)$ & \\
Digging stick & & $3.6(1)$ & $1.5(1)$ \\
Bark hut & $0.9(1)$ & $3.6(1)$ & & $3.0(2)$ \\
Net & & $3.6(1)$ & \\
Bag & & $3.6(1)$ & & \\
Harpoon & & & & \\
Paddle & $0.9(1)$ & $10.71(3)$ & $10(1)$ & \\
Text & $15.0(16)$ & & & \\
Harbour Bridge & $14.0(15)$ & $7.14(2)$ & $10(1)$ & \\
Australian map & $5.6(6)$ & & $10(1)$ & \\
Small boat & $4.7(5)$ & & $10(1)$ & \\
Ship & $2.8(3)$ & & & \\
Flag & $1.9(2)$ & $3.6(1)$ & & $1.5(1)$ \\
Horseshoe & $0.9(1)$ & $3.6(1)$ & & $1.5(1)$ \\
Star & & & & \\
Heart & & $10.7(3)$ & & \\
Spade symbol & & & & \\
Crest & & & & \\
Sun & & & & \\
City outline & & & & \\
Unidentified & & & & \\
\hline
\end{tabular}

Table 2: Object subject matter by percent and (number) on wooden objects by area 


\section{Regions and individuals}

The artefacts documented to date have been placed into ten style areas that share many features in common. An eleventh locality, just outside the main area of study, has also been included because of similar trends in artefact production. A few finds come from elsewhere within the region, such as some finely incised spear throwers with animal depictions that were collected mid-last century near Naracoorte, South Australia, but these have not yet been examined in detail. For the purposes of this paper, objects from four main areas (two in NSW, one in Victoria and one in South Australia) are discussed. These areas were chosen not only because they produced most of the surviving sample of wooden objects with figurative imagery but also because they have nearby bodies of figurative rock-art thought to have been made and used until shortly after European contact. Dates refer to the range of documented objects. A comparative summary of subject matter preferences can be found in Tables 1 and 2 .

\section{Coastal NSW, Kempsey to Nowra (1880-1970)}

La Perouse was the central distribution and manufacture point for this school of artists, who specialised in elaborately decorated boomerangs, shields, clubs and sometimes bullroarers. Nineteenth century pieces were mostly incised. Early twentieth century pieces were deeply poker-worked but in the 1930 s some patches of paint were added to enhance kookaburra breasts or water in landscapes. In the 1950 s paint was often used in combination with pokerwork, especially on large shields. Common animals include kangaroos, emus, kookaburras, possums and koalas. Kookaburras and possums are often depicted in tree branches while sprigs of vegetation, vines or leaves usually separate animal depictions. The Simms family of artists often featured a large cycad in the centre of boomerangs or shields and often semi-circles around edges (Figure 1). Sometimes human figures holding weapons, including spears, are illustrated, occasionally as if in combat. There are kangaroo hunting and cooking scenes, depictions of the First Fleet arriving in an Aboriginal land/seascape and elaborate illustrations of the Sydney Harbour Bridge (Figure 2). Many artists appear to have worked from the same templates, with the two most common consisting of: (a) a kookaburra in a branch, a kangaroo, a map of Australia, cycad or some other design in the centre, followed by an emu and a possum in a tree branch; (b) the Sydney Harbour bridge, framed with a kangaroo, emu, kookaburra and possum. 'La Perouse' or 'Sydney' was sometimes burnt on boomerangs; occasional pieces say 'Good luck' from places like Goodnight Island or advertise Koala Park, where boomerang lessons were once held. Sometimes special commemorative designs were made to honour Aboriginal sporting heroes. Some pieces were signed by artists or their names were written on the back of the object by others. Individual artists identified include Harry Cooley, A. Perrett, Ned Simms, Wesley Simms, J. Simon (Taree), Bert Timbery, Bob Timbery, Joe Timbery (Figure 3) and Albert Woodlands (Kempsey). Occasionally Tommy Foster, from Lake Tyers (Victoria), would visit and decorate boomerangs in either his Lake Tyers style or the local La Perouse way.

Ninety-four objects were sourced from museum and private collections, consisting of 73 boomerangs (77.7\%), 15 shields $(16.0 \%), 5$ clubs $(5.3 \%)$ and 1 bullroarer $(1.1 \%)$. On these, 351 animals are depicted, twothirds of them being kookaburras, kangaroos or emus (Table 1). There are 107 depictions of objects, half of them being spears or boomerangs (Table 2). In terms of plants, there are 9 depictions of cycads, numerous tree branches (upon which kookaburras and/or possums usually rest), various trees and floral motifs. Scenes include the arrival of Europeans, hunting and fishing.

\section{Inland NSW (1865-1970)}

The earliest artefact in the Australian Museum's collection was acquired by the first European settlers of an area near Wagga Wagga in 1865 (Figure 4). It includes illustrations of the new people on the land, as well as Roman numerals (van Toorn 2001) - something very different from early pieces that more often were plain or had geometric designs (Cooper 1994).

Most early pieces consist of deeply incised animal designs on clubs, boomerangs and parrying shields (Figure 1). One parrying shield has a depiction of a man

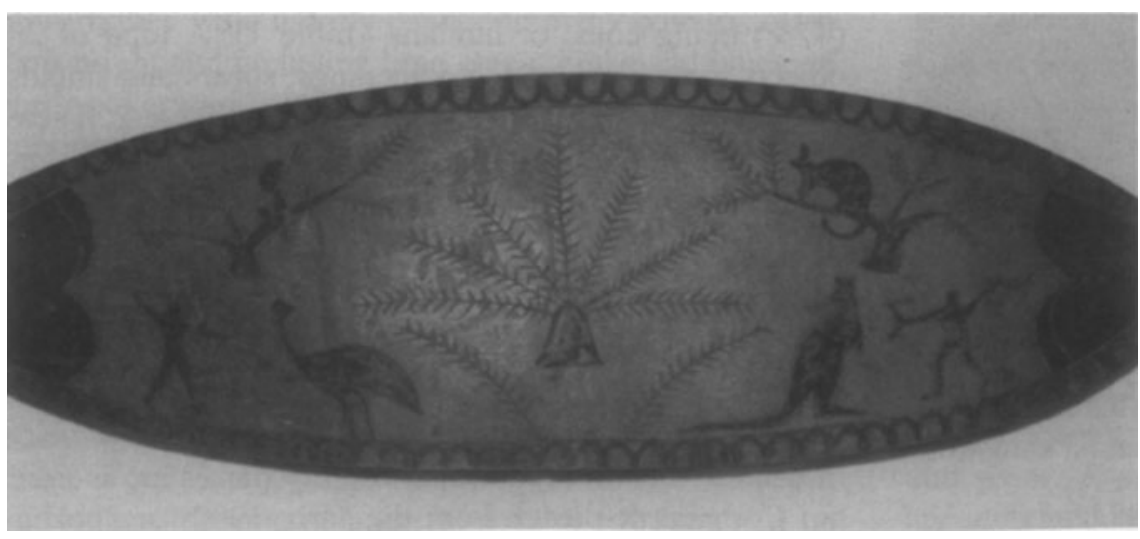

Figure 1. Shield attributed to Wesley Simms with a depiction of a cycad in the centre and half-circles around the edge (48 x $16 \mathrm{~cm}$; Australian Museum E92378). 


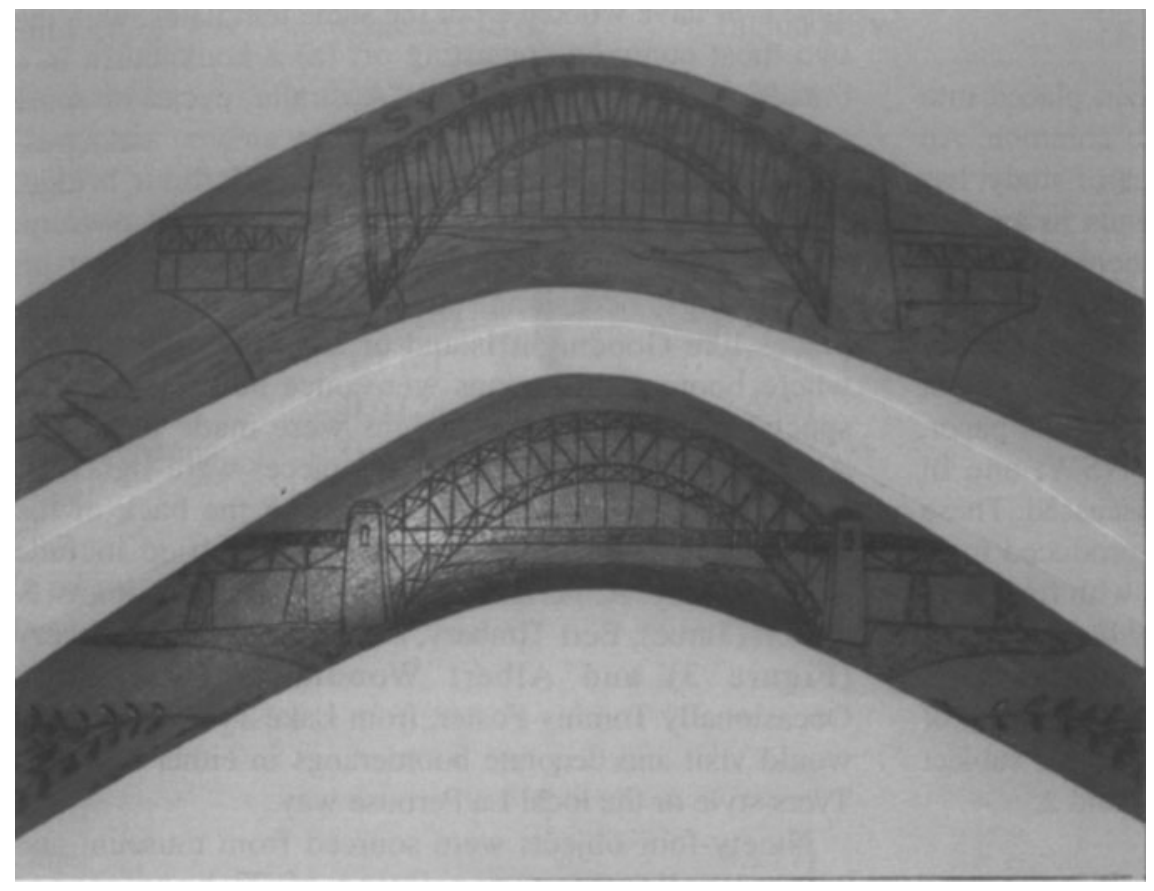

Figure 2. Close-up of two 1930s La Perouse boomerangs with Sydney Harbour Bridges, one with colour (bridge $33 \mathrm{~cm}$; Australian Museum E92408; private collection 59-43).

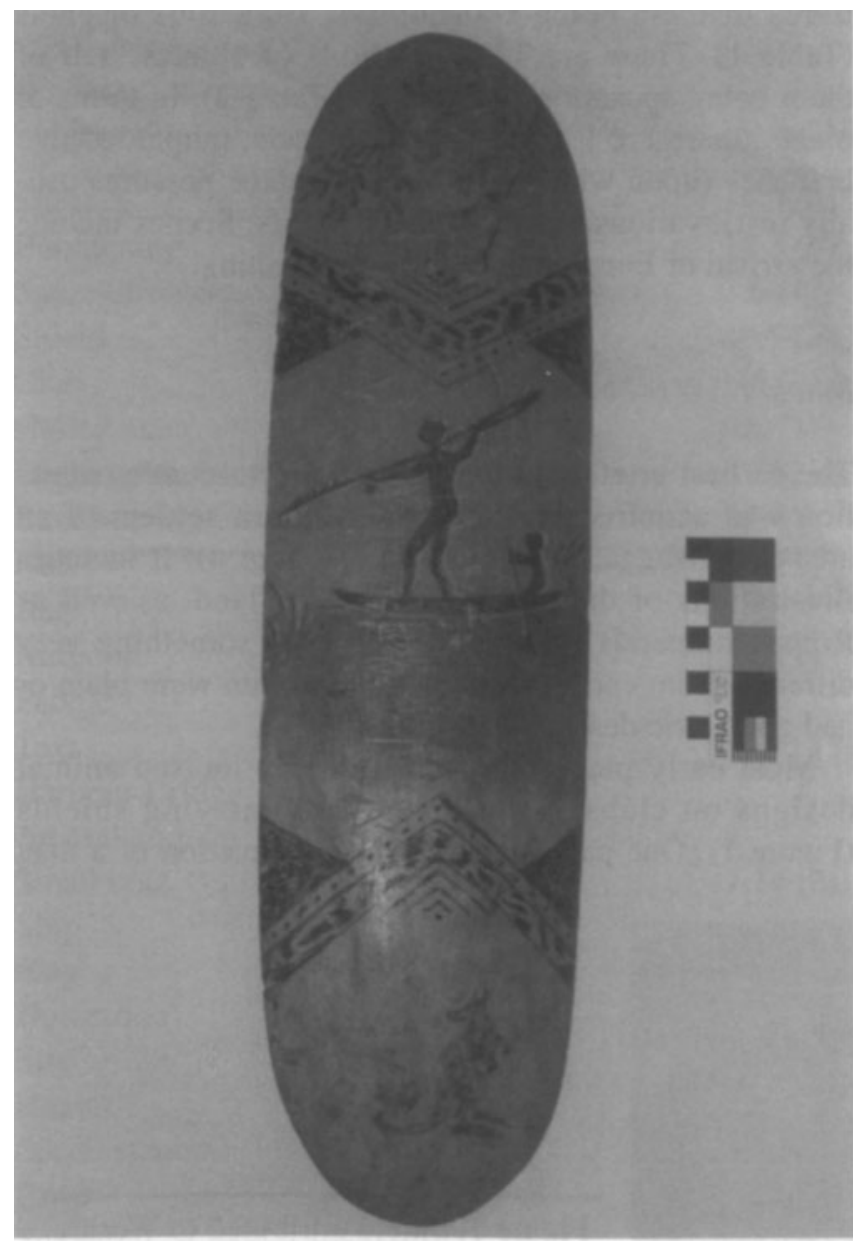

Figure 3. Shield by Joe Timbery featuring his distinctive triangular motifs, a fishing scene, a koala and a kangaroo (scale $10 \mathrm{~cm}$; private collection 59-3). holding a boomerang and club, goanna, snake, kangaroo, emu, concentric oval and a concentric diamond. 1930s objects are more often poker-worked boomerangs, sometimes with similarities to the Coastal NSW tradition, especially those from Condobolin with kookaburras. Wooden clap sticks with poker-worked centipedes are known from Cobar. Generally, pieces from this region are rare in collections and no individual artists have been identified.

Nineteenth century pieces are usually incised, with the earliest recorded consisting of clubs and stockwhip handles. Fine to faintly incised poker-worked animals in landscapes are common in material made between the early 1920s and 1970s (Figure 5), usually boomerangs and shields. Some 1920s pieces collected near Albury show similarities to Coranderrk and Echuca (Victoria) pieces, with half circles around the edges of boomerangs and shields. Recent material sometimes says 'Made by Wiradjuri Tribe' or there is a place name on the back.

Thirty objects were studied, 17 (56\%) being boomerangs, 4 (13\%) clubs, $3(10 \%)$ shields, $3(10 \%)$ walking sticks, $2(7 \%)$ clap sticks and one spear thrower. On these, there are 119 animal depictions, nearly half $(47 \%)$ being emus or humans (Table 1). A total of 28 objects were illustrated. Boomerangs, spears and shields were common but no one was dominant (Table 2. There are a few floral motifs, trees and a tree branch, as well as six landscape settings with animals, trees and topography. On one walking stick there is a ceremony scene and a depiction of someone spearing a fish from a boat.

\section{Victoria $(1850-1960)$}

In central Victoria, nineteenth century pieces are incised but Coranderrk pieces from the early 1900 s are poker- 

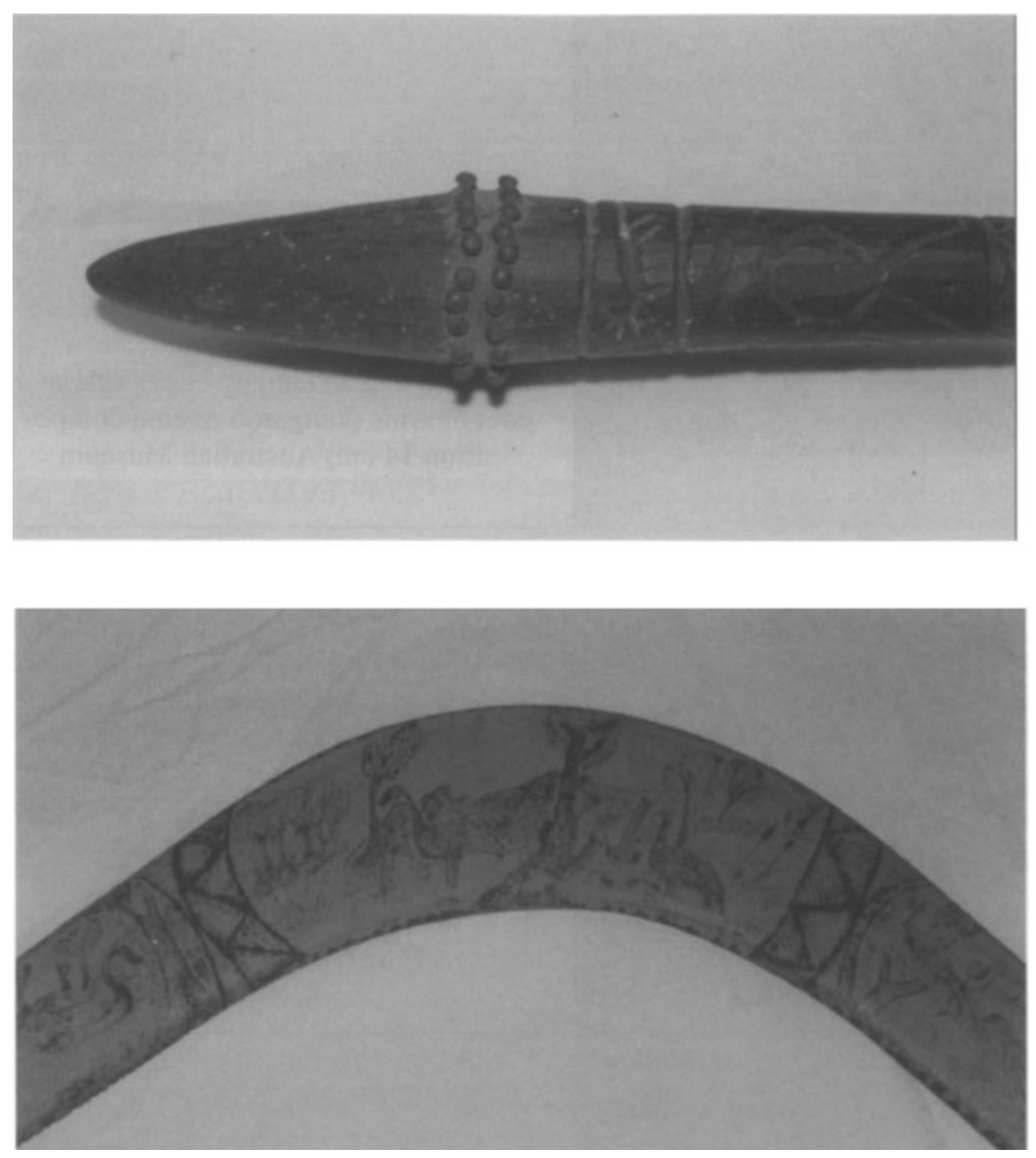

Figure 4. Top of an 1865 club from near Wagga Wagga, NSW with an engraved animal and a human figure wearing a hat, possibly a European (length shown $20 \mathrm{~cm}$; Australian Museum E77330).
Figure 5. Inland NSW boomerang with fine pokerwork scenes of animals in landscapes and 'Made in Australia by Wiradjeri Tribe' written on the back (central scene $15 \mathrm{~cm}$; private collection 22-1). worked. On nineteenth century incised objects solitary small animals such as lizards, emus, kangaroos or koalas are common. Sometimes there are depictions of humans with weapons and/or engaged in combat, or introduced subjects, such as a horse's head or sailing ship, are illustrated. Early twentieth century pieces have possums, swans, kookaburras and other birds. Half circle designs border edges of some boomerangs and shields from Coranderrk and Echuca.

For Lake Tyers, boomerangs are by far the most common object type, but occasionally clubs and shields were made. Initially, pieces were decorated with fine to medium pokerwork designs (Figure 6); from about 1949 onward they were usually painted in many colours, often very bright and including lime green, pinks and blues. In early pokerwork pieces, lyrebirds and kookaburras are common, along with an emu and kangaroo. In the 1930s, an emu and kangaroo were often depicted on either side of a shield/crest, suggestive of a coat of arms. Painted boomerangs (Figure 7) feature koalas, emus, kangaroos, a range of birds (including magpies) and occasionally a sailing ship. Curving vine designs often frame words and dates, or were used to separate animal depictions. In both poker-worked and painted pieces piles of half-circles, often in a 3-2-1 configuration, are common near each end of boomerangs. Names and dates are frequent on both poker-worked and painted pieces; often 'Good luck from Lake Tyers' has been burnt or painted on the boomerang. Artists include Lindsay Cobourne, Tommy Foster, Harold Hayes, William Johnson, Lawrey Moffit and Jim Mullet Senior.

For Lake Tyers, 35 objects were located for study, all boomerangs. On these there are 145 animal depictions and 10 objects. The four most common creatures are kookaburras, kangaroos, emus and koalas. Other creatures include 6 lyrebirds, 3 humans and 2 dogs (Table 1). Most objects are crests (6) but there also is a ship, a star, a horseshoe and, curiously, one portrayal of the Sydney Harbour Bridge (Table 2). The latter is by Tommy Foster and was made soon after a visit to Sydney. There are no plant motifs or scenes.

\section{Flinders Ranges, South Australia (1930-1970)}

Deeply incised boomerangs, shields, walking sticks and containers such as bowls and boxes are common. Figures are in relief and usually singed black. These are set off from a non-burnt background consisting of hundreds of small knife cut-marks. The variety of animals and scenes is impressive. Usually different depictions are separated by solid or geometric infilled bands; when 


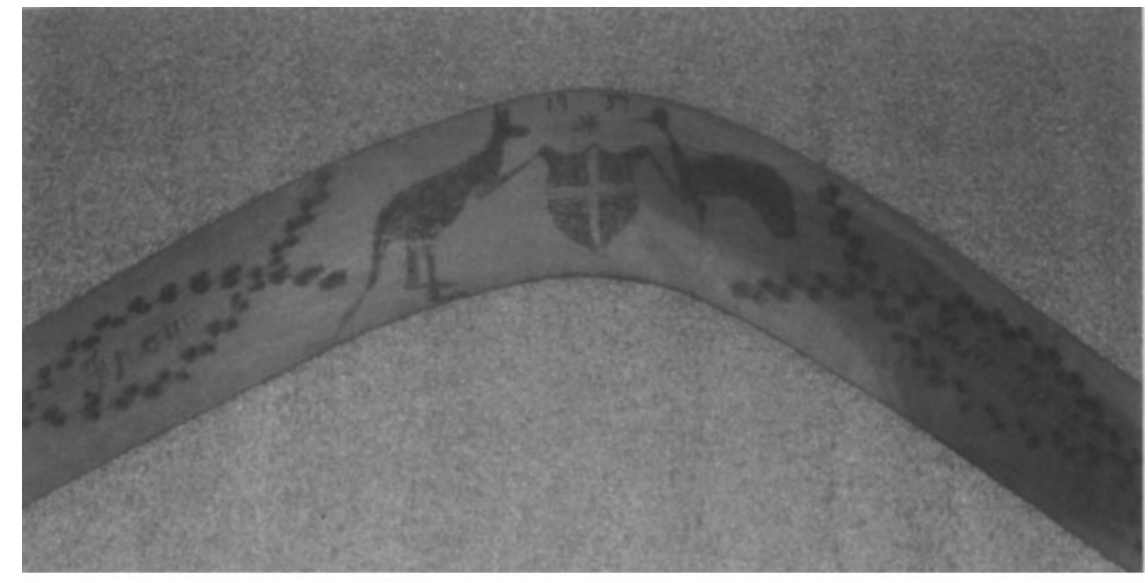

Figure 6. 1937 Lake Tyers boomerang with pokerwork designs and featuring a kangaroo and an emu on either side of a coat of arms (kangaroo \& emu composition $14 \mathrm{~cm}$; Australian Museum E92393).

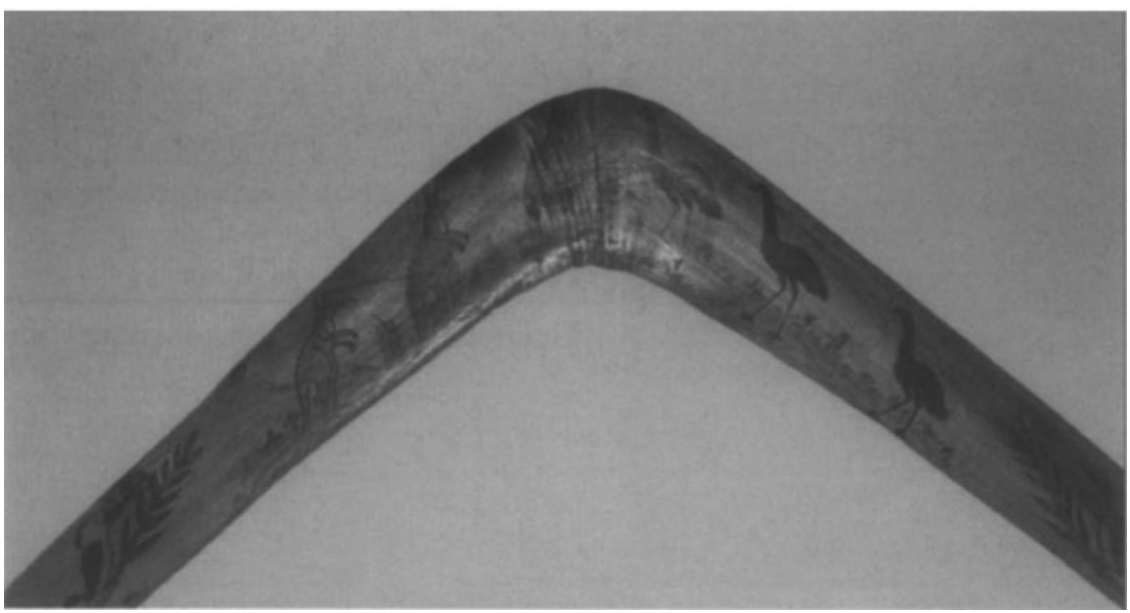

Figure 7. 1950s Lake Tyers boomerang with painted animal designs $(57 \times 27$ $\mathrm{cm}$; private collection 59-8).

a series of events is portrayed the separating bands divide the action into 3-5 'snapshots', with resemblance to a series of contemporary cartoon panels. These are often 'read' from right to left, but on some boomerangs they are 'read' left to right and on shields from top to bottom. Common scenes include ceremonial performance (Figure 8), hunting kangaroos with dogs (Figure 9), rodeo/stockman activities (Figure 10), fighting, a goanna wrestling with a snake, and animals in landscapes. Animals depicted include kangaroos, emus, ducks, swans, horses, dogs, eagles and goannas, the last two of which are significant Dreaming creatures associated with the creation of the Flinders ranges. Other creatures include scorpions, bush flies and a range of beetles, butterflies and moths. Artists identified to date include Ted Coulthard, Davey Ryan and Henry Wilton but pieces were not signed.

A total of 50 objects were examined in detail: 31 boomerangs, 8 shields, 4 coolamons , 3 walking sticks, a spear thrower, a wooden box, a wooden bowl and a tube. On these, there were 337 depictions of animals or humans and 65 depictions of objects. The Flinders Ranges sample has the biggest range of animal imagery (Table 1). The most common animal motifs consist of kangaroos, emus and humans. Most objects were portrayed in association with humans, boomerangs being most common, followed by spears and clubs (Table 2). Plants are rare, with only four flower images.

\section{Implications of results}

Many aspects of the results need detailed exploration, including changes in imagery associated with larger historical processes Aboriginal people were embedded in, the changing nature of Aboriginal-European interaction from 1850 to 1970 , the specific nature of local influences, sources of subject inspiration, economic impacts and so forth. However, because this is beyond the scope of one paper, we focus on the central change that occurred over time, the increased use of figurative motifs on wooden objects. There appear to have been many reasons for their widespread adoption but all are related to the impacts of colonisation. For instance, trade with Europeans may have stimulated a movement toward figurative designs in south-east Australia, much as it has in central Australia since the 1970s (Cooper 1994:108-09). Indeed, some Europeans may have actively encouraged the production of objects with figurative imagery and 

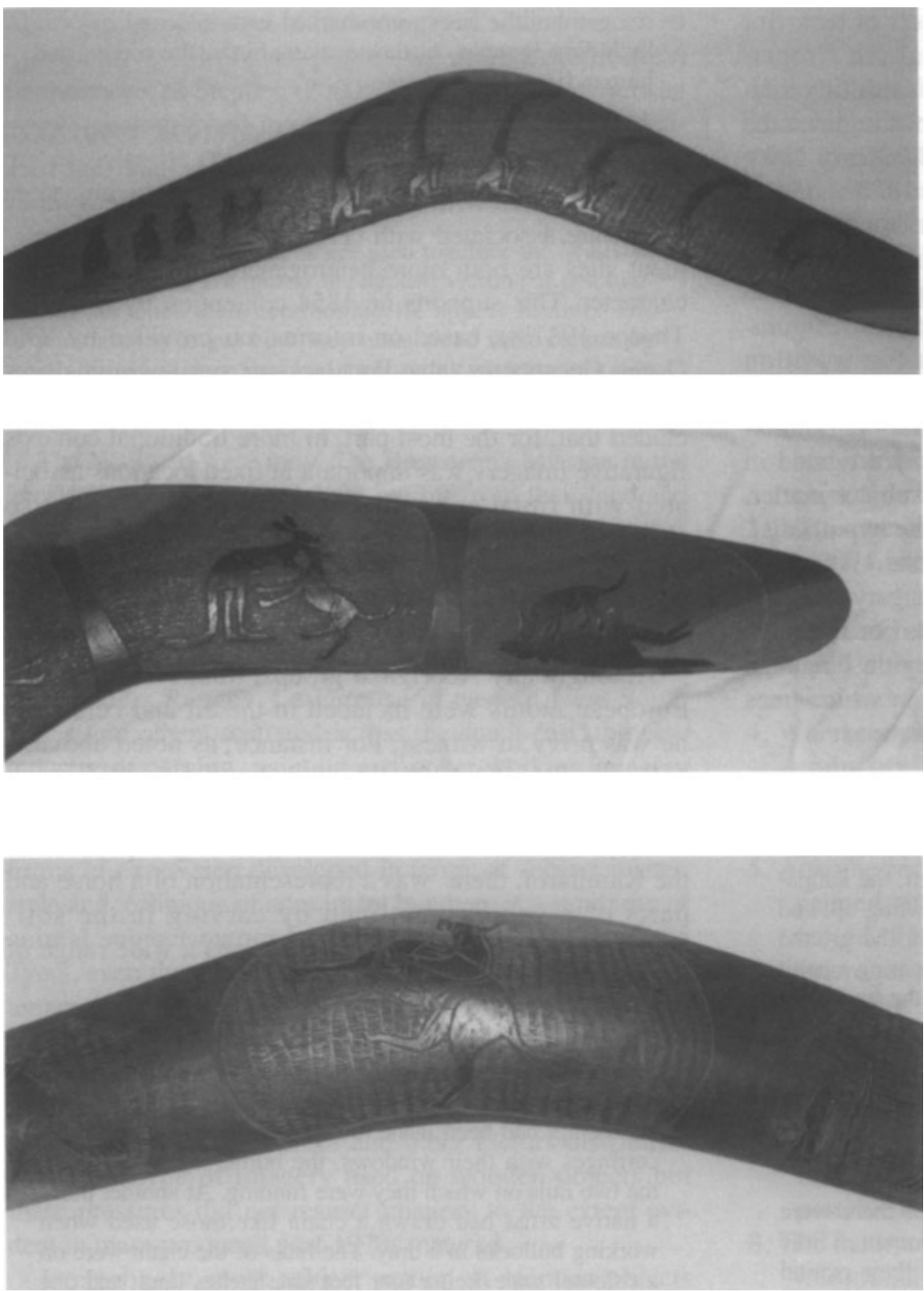

Figure 8. Flinders Ranges boomerang with ceremonial scene attributed to

Davey Ryan (length $59 \mathrm{~cm}$; Australian Museum E92370; purchased with funds donated by Lucy Turnbull).

Figure 9. Right side of a Flinders Ranges boomerang showing two of four panels of a hunting scene involving a dog (length $45.5 \mathrm{~cm}, 27 \times 7 \mathrm{~cm}$ shown; private collection 1-14).
Figure 10. Centre of a Flinders Ranges boomerang with rodeo/stockman scenes (central image length $18 \mathrm{~cm}$; Australian Museum E92379).

objects such as breastplates given to Aboriginal people usually included the figurative (especially kangaroos, emus and sprigs of vegetation). However, distribution networks for artefacts of the south-east, the changing nature of trade and the precise role of Indigenous people in it has not yet been described on a large scale. Indeed, only recently have these been documented for select south-east Australian communities, such as Lake Tyers in Victoria (see Kleinert 1994, 1997) or certain parts of New South Wales (Hooper in prep.; Wells 1993).

One of the key results of studies of trade in artefacts in south-eastern Australia is that changes in artefact production not only resulted from the nature of contact and trade situations but also from the wider effects of European colonisation. For instance, dispossession from land and the erection of barbwire fences radically affected access to natural resources, resulting in changes in the types of wood used for objects (Hooper in prep.).
The introduction of metal and metal tools also transformed the way in which things were made, allowing engraved imagery to be more easily made and making pokerwork designs possible. Money earned from the sale of artefacts affected production and at many locations power struggles between Aboriginal artists, missions and government officials took place over control of profits. Furthermore, the economics behind the trade led to greater degrees of self-determination, something often frowned upon by officialdom (Hooper in prep.; Kleinert 1994, 1997; Wells 1993).

Another very important consideration is the context of figurative imagery production and use prior to, at and shortly after European contact. At these times, wooden objects were mostly unadorned, with only rare examples from the late 1700 s and early 1800 s containing figures (Cooper 1994). However, engraved and/or painted figures of animals, humans, Ancestral Beings and objects were 
made at rock-art sites, on trees and on sheets of bark (for a summary of early southeastern material see GrogerWurm 1973). Many creatures were also faithfully rendered as ground drawings or sculptures throughout the south-east (e.g. see Henderson 1832:145-47; Kerry 1899; Mathews 1894, 1896, 1897a, 1897b, 1897c, 1901; Mathews and Everitt 1900; Stephen 2000).

We hypothesise that figurative art on portable wooden and other objects, such as carved emu eggs, developed out of these earlier landscape-based traditions of figurative art. We also propose that the portable tradition developed in direct response to people being moved away from traditional landscapes, to settlements, missions and large camps. This needs to be investigated in detail, especially in terms of comparing subject matter, but preliminary research lends support to the hypothesis.

Studies both in the late 1800 s and the late 1900 s conclude that much of the 'ground and tree' imagery was produced in a ceremonial or 'sacred' context. For instance, for the Darkinjung and related Sydney region language groups, Mathews notes the sacred context in which trees were marked with animal depictions for initiations:

Scattered here and there around the circle and amongst the images and designs on the ground were a number of marked trees, on the bark of which were carved representations of the emu, the wombat, the opossum, the kangaroo, the 'iguana', the 'squirrel', a snake crawling up, and other figures. On a log, which was lying on the ground near by, was cut the figure of a turtle, representing a habit which that animal has of lying on a log on the bank of a water-hole (Mathews 1897b: 3).

For the nearby Wiradjuri there is a more detailed description of both ground figures and those on trees, as this extract from Mathews (1901:36-37) illustrates:

Three yards beyond the archway referred to there were cut into the turf the figure of a man and a woman, a little less than life-size, lying side by side, with their genital organs conspicuously displayed. Not far from this pair was the effigy of a man formed by stuffing a suit of European attire with grass and leaves. This was propped up to keep it in an erect posture, giving it the appearance of a sentry on the watch. A little further on the outline of an immense snake, called the Waliwee, was cut in the ground.

At the distance of 130 paces from the archway (or 371 paces from the boorbung), still going towards the gombo, a colossal horizontal representation of Baiamai [a major culture hero that figures in the art, ceremony and oral history of many Aboriginal peoples of south-east Australia], eight feet six inches long, and five feet ten inches across the chest, was formed by heaping up the loose earth into human shape... and near him was a boomerang and weapons cut in the soil.

Between Baiamai and the gombo, a kangaroo was outlined by a groove in the soil, with a rear spear inserted in its body. This spear was supposed to have been thrown by Baiamai before he slipped and fell where he is now lying.

Besides the foregoing there were represented on the ground an iguana, a fish, an emu, a bullock, some birds' nests, a death-adder, a pig, and other things...

On both sides of the path, between the archway and the gombo, the trees were marked with different objects, including iguanas, turtles, snakes, birds, the moon, and human figures.

In terms of rock-art, both McDonald (1994, 1999, 2000) and later AMBS Consulting (2001) conclude that rock engraving sites with figurative imagery in the Sydney region are associated with ceremonial activity while pigment sites are both more heterogeneous and domestic in character. This supports an 1854 contention by Miles (in Thorpe 1931:8), based on information provided by 'Old Queen Gooseberry', that Port Jackson rock engraving sites were sacred spots visited for ceremony. Thus it can be concluded that, for the most part, in more traditional contexts figurative imagery was important at fixed locations associated with ritual and religious activity and was not so important as something to adorn portable objects. But after the cultural disruption and dislocation of European contact the reverse became true, perhaps partly because people became cut off from their key ritual landscape sites.

Among many Aboriginal groups, Mathews noted that European motifs were included in the art and ceremony he was privy to witness. For instance, as noted above, a bullock was carved into the ground and a European suit was used to make a human sculpture among the Wiradjuri (Mathews 1901). Among other groups, such as the Kamilaroi, there 'was a representation of a horse and parts of a vehicle, outlined by carving in the soil' (Mathews 1894:110). At some locations a wide range of European-inspired imagery could be found:

The imitative faculties of the natives were displayed in a few drawings, copied from scenes in the life of the white men, which were intermixed with the others. At one place an attempt had been made to represent a railway train, the carriages with their windows, the numerous wheels, and the two rails on which they were running. At another place a native artist had drawn a chain like those used when working bullocks in a dray. The links of the chain were on a colossal scale, being four feet nine inches long, and one foot three inches wide. The chain was close to the raised figure of the bullock previously described. Another draftsman, apparently a poker player, had succeeded in representing the four aces. Four rectangular spaces, about two feet long and eighteen inches wide, were first made side by side to indicate four cards, and on the middle of each of them one of the aces was delineated (Mathews 1897a:146).

Although Mathews (1896:36, 1897a:146) appears to have looked down on depictions of introduced subject matter, labelling them imitation and referring to Aboriginal 'imitative faculties', these designs are in fact very symbolic of wide concerns. By deliberately incorporating change in a visual manner, connections and relevance of traditional practice and identity were maintained in a rapidly changing world. Swain (1993:144), for instance, concludes that the aim of ceremonies that included European imagery 'was not to naively return to a pristine pre-colonial life by destroying Whites, but to maintain Aboriginal identity within the cosmos by demarcating its place within postcolonial society. In brief it aimed to define invasion as a morally controllable act'. One could also argue that what 
Aboriginal people were in fact doing was adding perceived European symbols of power to their ceremonies. Furthermore, as Stephen (2000:253) notes for the Wailwan people photographed in ceremony by Kerry (1899), identity can also be enhanced by incorporating European elements into indigenous art and ritual:

When all the photographs are seen together the Wailwan in the camp do not appear the hapless victims of colonialism nor does their ceremonial life appear remote. The photographs reveal how they maintained their culture by adapting various European elements in a remarkable expression of cultural identity in the face of occupation.

The Wailwan were moved to Brewarrina Mission in the late 1920s (Stephen 2000:252), cut off from their land and sacred sites between the Macquarie and Castlereagh rivers of western New South Wales. There they met other people, some of whom they knew as former neighbours or visitors to ceremony. In this environment, as at other missions and settlements such as Lake Tyers in Victoria, Nepabunna in the Flinders Ranges, La Perouse in eastern New South Wales and others scattered across the south-east, the new industry of carving, painting and poker-working imagery on wooden objects began to emerge. By the 1930s it was thriving, reaching a peak in the 1940 s and 1950s. Regional forms of expression developed in terms of subject matter, style and technique of adornment but there is a similarity of animal subject matter between coastal NSW and Lake Tyers, even though technique, style and other subject matter are different. A vigorous 'tourist art' developed but both the objects and the images carried strong messages of Aboriginal identity in a rapidly changing world. This continues today in similar and new media. Of course, consumer tastes, market forces and other factors also influenced the type of imagery used on wooden objects but these pressures did not restrict imagery to the extent evident in mass-produced post-1970s material.

Interestingly, most subject matter on wooden objects from each region continued to be animals important to the people and associated with their traditional lands, scenes of traditional activity and indigenous artefacts. Indeed, in the Flinders Ranges sample $86 \%$ of objects depicted are indigenous, while $64.5 \%$ of objects depicted on artefacts from inland New South Wales are Aboriginal, as are $52.3 \%$ from coastal New South Wales. The Lake Tyers, Victoria material only shows ten objects but all are of non-Indigenous origin. It appears then that external market forces and internal decisions about important subject matter reflective of identity worked together to perpetuate the production of figurative imagery that illustrated native wildlife, Aboriginal material culture and scenes of traditional activity for each area. However, internal decision making may have led to the addition of non-Aboriginal objects to some pieces, as well as some scenes of a non-traditional nature, as there are suggestions those pieces were not as marketable. Although they told important stories to others about change and survival, they were not considered as 'authentic' by the non-Aboriginal purchaser.

\section{Conclusions}

Although we have only presented preliminary results, there are many conclusions that can be drawn from this study of changing patterns of figurative imagery production in south-east Australia. Some of the more important for theory and model building include:

1. Culture contact results in new forms of imagery, new contexts of production and shifts in subject matter, with group experience and individual conscious decision-making determining the nature of response.

2. Intimate relationships to other creatures, particularly animals of one's 'country', are commonly expressed both at rock-art sites and, more recently, on portable objects.

3. 'Connection to land' is a central theme that pervades much historic and recent Aboriginal visual and religious activity. It is this that is the key link between ancient rock-art, historic ceremonial practices, socalled 'tourist art' and contemporary visual expression and performance.

4. When people are cut off from ritual landscapes where enduring marks can be made, visually oriented expressions of experience and belief can become more common on portable objects.

5. At some rock-art sites, especially more heterogeneous painted sites, aspects of history are sometimes portrayed. This is true of some portable objects with heterogeneous imagery as well.

6. The production of visual art in both fixed and portable contexts involves incorporating the past into a changing present that has both meaning and cultural relevance for individuals and groups.

7. Different aspects and levels of individual versus group identity can be identified at rock-art sites and on portable objects.

8. The incorporation of new, introduced images with old, traditional désigns can strengthen Indigenous identity in changing circumstances, as new experiences are interpreted within a larger traditional but changing context.

9. The use and acquisition of timbers and other natural resources allowed for the continuation of a range of tradition as well as providing a vehicle for cultural traditions to be passed on to future generations.

10. The production of artefacts for sale is an example of Aboriginal concerns for independence from government handouts, mission control of lives and so forth.

A central theme that emerged from the above is that as change in human environments increases so does the desire to record and incorporate change as much as possible, for both internal and external audiences (Taçon 1999). In other words, a fundamental response to intense cultural change is to express it in material form. Cultural survival and revival can be enhanced by this process of material expression, with benefits for individuals as well as groups (e.g. Dissanayake 1992, 1995). Thus wooden and other artefacts, especially pieces with figurative 
imagery, functioned not only to communicate outside traditional culture to the non-Indigenous tourist, scholar or curio collector but also to the members of the artist's culture. As Graburn (1999:345) notes:

We now realize that practically all the objects in our ethnographic collections were acquired in politically complex, multicultural colonial situations. Furthermore, we can state unequivocally in our analyses that unless we include the sociopolitical context of production and exchange in our analyses we will have failed in our interpretation and understanding.

However, until recently, many of these sorts of objects were marginalised, considered less meaningful, unimportant or too heavily influenced by outsiders. For instance, some of the objects we examined from early museum collections had 'degenerate modern' written on them by ill-informed past curators because they were adorned with skillfully produced and faithfully rendered figurative imagery. Indeed, it appears that what Phillips (1999:34) notes for the rest of the world is still pertinent in Australia today: 'Past generations of ethnologists and art historians not only have failed to recognize the mediating role of souvenir and other transcultural arts but also have actively devalued them, damning them as acculturated and therefore "degenerate," and as commercial and therefore inauthentic'. In this study, this notion is confronted directly, with the value of such objects from south-east Australia demonstrated to be anything but inauthentic or degenerate.

The switch from landscape sites to portable wooden objects for figurative imagery in south-eastern Australia is similar to the switch from rock-art sites to portable and tradeable bark paintings across the Top End of the Northern Territory. Many of the same responses to change and incorporation of the new can be documented in detail (e.g. Taylor 1987), although paintings on bark in shelters have a pre-contact history. In south-eastern Australia, there were many reasons why a thriving industry of wooden objects with elaborate figurative imagery developed but an overriding motivation appears to be that it was these sorts of objects that best allowed Aboriginal men to express their Aboriginality in a way acceptable to Europeans. Aboriginal people were divorced from their traditional lands, were banned from practicing ceremony at sacred sites and rock-art production had ceased. But depictions of important creatures, places and experiences could be made on wooden objects, for gift giving, trade and sale. Europeans responded positively to such objects and their production brought in a handsome income for Aboriginal makers. Just as the past production of figurative imagery at landscape sites reaped spiritual, social and economic rewards so too did depictions on portable wooden artefacts. Eventually, from the late 1960 s onward, and with promising young Aboriginal artists sent to Western art schools, this gave rise to the great body of Koori visual art, both rural and urban, the region is famous for today (e.g. see Mundine 1990; Onus 1992). The process of transformation and incorporation will undoubtedly continue but ancient roots in land, other creatures and indigenous spirituality will likely remain both strong and deep. Indeed, there are moves to reinvigorate rock-art sites and carved, painted and pokerwork wooden objects continue to be made for spiritual, economic and political purposes.

\section{Acknowledgments}

Many people and institutions are thanked for access to their collections, advice and information. These include Kathryn Wells in Canberra; Philip Clarke and Philip Jones, South Australian Museum, Adelaide; Carol Cooper, AIATSIS and later National Museum of Australia, Canberra; Susie Davies, Macleay Museum, Sydney; David Kaas, National Museum of Australia, Canberra; and Gaye Sculthorpe and Melanie Raberts, Victoria Museum, Melbourne. Ngiyampaa elder 'Chief' (Kevin Peirpoint) is especially thanked for sharing his traditional knowledge. Numerous private collectors, some of whom wish to remain anonymous, are also extended great gratitude for sharing their objects and collections. Nancy Land and Robert Croll are specifically thanked for allowing their objects to be photographed and reproduced in this paper. Lucy Turnbull is greatly thanked for donating funds for the purchase of outstanding pieces for the collection. Andrée Rosenfeld and an anonymous referee are thanked for comments that vastly improved the paper. All photographs are by P.S.C. Taçon/Australian Museum. This research was supported by an Australian Museum Research Grant administered through the People and Place Research Centre. Finally, Annie Clarke and Alistair Paterson are thanked for the invitation to submit a paper to this special volume.

\section{References}

AMBS Consulting 2001. Somersby Industrial Estate: plan of management for Aboriginal heritage (3 volumes). Unpublished report for Gosford City Council.

Amos, P.B. 1976. Pidgin languages and tourist arts. Studies in the Anthropology of Visual Communication 4:128-39.

Appadurai, A. 1986. The social life of things: commodities and the politics of value. Cambridge University Press, Cambridge.

Chippindale. C. and P.S.C. Taçon (eds.). The archaeology of rock-art. Cambridge University Press, Cambridge.

Cooper, C. 1994. Traditional visual culture in south-east Australia. In A. Sayers (ed.), Aboriginal artists of the nineteenth century, pp. 91-109. Oxford University Press, Melbourne.

Dissanayake, E. 1992. Homo Aestheticus: where art comes from and why. University of Washington Press, Seattle.

Dissanayake, E. 1995. Chimera, spandrel, or adaptation: conceptualizing art in human evolution. Human Nature 6(2):99-117.

Graburn, N.H.H. 1976. Ethnic and tourist arts: cultural expressions from the fourth world. University of California Press, Berkeley.

Graburn, N.H.H. 1999. Ethnic and tourist arts revisited. In Phillips, R.B. and C.B. Steiner (eds.), Unpacking culture: 
art and commodity in colonial and postcolonial worlds, pp.335-53. University of California Press, Berkeley.

Groger-Wurm, H.M. 1973. Australian Aboriginal bark paintings and their mythological interpretation. Volume 1: Eastern Arnhem Land. Australian Institute of Aboriginal Studies, Canberra.

Henderson, J. 1832. Observations on the colonies of New South Wales and Van Diemens Land. London.

Hooper, S.B. In prep. Things of stone and wood, Aboriginal tools and weapons of southeastern Australia. Tribal Artifacts, Blue Mountains.

Jules-Rosette 1984. The messages of tourist art: an African semiotic system in comparative perspective. Plenum Press, New York.

Kerry, C. 1899. 'Exhibits'. Journal and Proceedings of the Royal Society of New South Wales 33:xxvii-xxviii.

Kleinert, S. 1994. "Jacky Jacky was a smart fella": a study of art and Aboriginality in south east Australia 1900-1980. $\mathrm{Ph} . \mathrm{D}$ thesis, Australian National University, Canberra.

Kleinert, S. 1997. Aboriginal landscapes. In G. Levitus (ed.), Lying about the landscape, pp. 82-99. Craftsman House, North Ryde.

Kleinert, S. 2000. Art and Aboriginality in the south-east. In S. Kleinert and M. Neale (eds.), The Oxford Companion to Aboriginal art and culture, pp. 240-47. Oxford University Press, Oxford.

Mathews, R.H. 1894. Aboriginal Bora held at Gundabloui in 1894. Journal and Proceedings of the Royal Society of New South Wales 28:98-129.

Mathews, R.H. 1896. Australian ground and tree drawings. American Anthropologist IX:33-49.

Mathews, R.H. 1897a. The Bora of the Kamilaroi Tribes. Proceedings of the Royal Society of Victoria 9:137-73.

Mathews, R.H. 1897b. The Burbung of the Darkinung Tribes. Proceedings of the Royal Society of Victoria 10:1-12.

Mathews, R.H. 1897c. The Burbung of the New England tribes, New South Wales. Proceedings of the Royal Society of Victoria 9:120-36.

Mathews, R.H. 1901. The Burbung of the Wiradthuri tribes. Proceedings of the Royal Society of Queensland 16:35-38.

Mathews, R.H. and M.M. Everitt. 1901. The organisation, language and initiation ceremonies of the Aborigines of the south-east coast of NSW. Journal and Proceedings of the Royal Society of New South Wales 34:262-81.

McDonald, J. 1994. Dreamtime Superhighway: an analysis of Sydney Basin rock art and prehistoric information exchange. Unpublished PhD thesis, Australian National University, Canberra.

McDonald, J. 1998. Shelter rock-art in the Sydney Basin - a space - time continuum: exploring different influences on stylistic change. In C. Chippindale and P. Taçon (eds.), The archaeology of rock-art, pp. 319-35. Cambridge, University Press, Cambridge.

McDonald, J. 1999. Bedrock notions and isochrestic choice: evidence for localised stylistic patterning in the engravings of the Sydney region. Archaeology in Oceania 34(3):145-60.

McDonald, J. 2000. Media and social context: influences on stylistic communication networks in prehistoric Sydney. Australian Archaeology 51:54-63.
Morphy, H. (ed). 1989. Animals into art. Unwin Hyman, London.

Morphy, H. 1998. Aboriginal art. Phaidon Press Limited, London.

Mundine, D. 1990. Black on black: an Aboriginal perspective on Koori art. In W. Caruana and J. Isaacs (eds.), The land, the city: the emergence of urban Aboriginal art. Art Monthly Australia (supplement): 7-9.

Onus, L. 1992. Introduction. In C. McGuigan (ed.), New tracks old land: contemorary prints from Aboriginal Australia, pp. 4-5. AAMA, Surrey Hills

Phillips, R. 1999. Nuns, ladies, and the "Queen of the Huron": approaching the savage in Nineteenth-Century Huron tourist art. In Phillips, R.B. and C.B. Steiner (eds.), Unpacking culture: art and commodity in colonial and postcolonial worlds, pp.33-50. University of California Press, Berkeley.

Phillips, R.B. and C.B. Steiner (eds.). 1999. Unpacking culture: art and commodity in colonial and postcolonial worlds. University of California Press, Berkeley.

Ross, M. 2001. Emerging trends in rock-art research: huntergatherer culture, land and landscape. Antiquity 75:543-48.

Sayers, A. 1994. Aboriginal artists of the 19th century. Oxford U. Press, Melbourne

Sculthorpe, G. 1996. Punu Tjuta. Change and innovation in Western Desert carving. PhD thesis, La Trobe University, Melbourne.

Stephen, Ann. 2000. Reclaiming Wailwan culture. In Kleinert, $\mathrm{S}$. and $\mathrm{M}$. Neale (eds.), The Oxford companion to Aboriginal art and culture, pp.251-54

Swain, T. 1993. A place for strangers: towards a history of Australian Aboriginal being. Cambridge University Press, Cambridge.

Taçon, P.S.C. 1999a. All things bright and beautiful: the role and meaning of colour in human development. Cambridge Archaeological Journal 9(1):120-26.

Taylor. L. 1987. 'The same but different': social reproduction and innovation in the art of the Kunwinjku of western Arnhem Land. Unpublished PhD thesis, Australian National University, Canberra.

Thomas, N. 1991. Entangled objects: exchange, material culture and colonialism in the Pacific. Harvard University Press, Cambridge.

Thorpe, W.W. 1931. Early references to Aboriginal rock carvings. Mankind 1(1):7-11.

Torrence, R. and Clarke, A. (eds.). 2000. The archaeology of difference. Negotiating cross-cultural engagements in Oceania. Routledge, London.

van Toorn, P. 2001. Transactions on the borderlands of Aboriginal writing. Social Semiotics 11(2):209-27.

Vastokas, J. 1987. Native art as art history: meaning and time from unwritten sources. Journal of Canadian Studies 21(4):7-36.

Vastokas, J. 1994. Are artifacts texts? Lithuanian woven sashes as social and cosmic transactions. In S.R. Riggins (ed.), The socialness of things: essays on the socio-semiotics of objects, pp. 337-62. Mouton de Gruyter, Berlin.

Wells, K. 1993. Aborigines trading artefacts with Europeans: south-eastern Australia 1860s - 1920s. Unpublished MLitt thesis. Australian National University, Canberra. 